\title{
Design, layout e sistemas tipográficos
}

Design, layout and typographic systems

MOTA, Marcelo José da

Universidade do Oeste Paulista - UNOESTE I motamj@uol.com.br

AMENDOLA, Mariangela Barbosa Fazano

Universidade do Oeste Paulista - UNOESTE I mariangelafazano@gmail.com

\section{Resumo \\ Este artigo busca uma reflexão acerca da linguagem \\ Abstract} tipográfica, algumas constatações históricas sobre o tema e sobre os sistemas tipográficos e suas utilizações no âmbito do design gráfico. Foram empreendidas pesquisas exploratórias em bibliografia da área, que apontaram algumas formas de articular sistematicamente a linguagem tipográfica na busca de evidências que permitam identificar onde $\mathrm{o}$ uso de instrumentos de pesquisa adequadamente escolhidos pode fazer uma significativa diferença nas tomadas de decisão de projeto. A principal contribuição deste trabalho é servir de guia para estudantes e pesquisadores em design gráfico, na tentativa de aproximar a prática projetual dos conceitos metodológicos sobre a linguagem tipográfica e os sistemas que a compõem, visando uma maior adequação do discurso teórico-prático deste profissional.

Palavras-Chave: Linguagem Tipográfica. Sistemas Tipográficos. Design Gráfico.

This paper presents a reflection on typographic language, historical findings about the theme and about typographic systems, and their uses in the field of graphic design. Exploratory researches were undertaken in the literature body, revealing approaches to a systematic articulation of the typographic language, including the search for evidence on how the use of research tools can make a significant difference in supporting decision-making. The main contribution of this work is to serve as a guide for graphic design students and researchers, in order to connect the design practice of methodological concepts about typographic language and the systems it embodies, aiming at a better adaptation of the theoretical-practical discourse of such professionals.

Keywords: Typographic language. Typographic systems. Graphic design. 


\section{LINGUAGEM TIPOGRÁFICA E DESIGN}

Os tipos gráficos aparecem com a invenção da escrita derivada de diferentes regiões do mundo, no desenvolvimento independente de várias formas de representação da fala, em um período de tempo indeterminado. Há milênios, anteriores a era cristã, já havia tecnologia de construção tipográfica empregada para comunicar uma ideia ou o pensamento. A geometria aplicada na construção e na visualização de símbolos para codificar uma ideia, uma ação ou pensamento de antigas civilizações, contribuíram para os princípios básicos da formação e composição dos desenhos tipográficos contemporâneos. Há registros de desenhos de tipos móveis na China, mas devido à complexidade de impressão e milhares de caracteres não foram muito úteis. Enquanto que no ocidente, com influências continentais foi criado o alfabeto latino que conseguiu traduzir geometricamente e mecanicamente sinais apropriados para utilização.

Há quatro mil anos A.C., os sumérios criaram um sistema de leitura pictórica na combinação de sinais gráficos estilizados com uma geometria simplificada e que representavam coisas e objetos. Ao final do último milênio, A.C., surge em regiões próximas ao Oriente Médio diferentes tipos de alfabeto e escrita, com sofisticação de desenhos e estruturas de variadas línguas, nas quais emprestaram sua tecnologia aos povos. Neste mesmo momento, na Europa, houve a evolução mais significativa para a história da escrita: a criação do alfabeto greco-latino. A geometria aplicada na construção e na visualização de símbolos para codificar uma ideia, uma ação ou pensamento de antigas civilizações, contribuíram para os princípios básicos da formação e composição dos desenhos tipográficos contemporâneos (MOTA, 2009).

Frutiger (2009, p.118), escreve que:

[...] num espaço relativamente curto, o alfabeto fenício atingiu determinada perfeição da forma e reduziu-se a 22 sinais fonéticos selecionados. Por isso, não nos surpreende o fato de esse sistema de escrita ter substituído, com certa rapidez, quase todos os demais. Sendo assim, no decorrer do primeiro milênio antes de cristo, os aramaicos difundiram o alfabeto como meio internacional de comunicação por todo o Oriente Próximo, chegando ao Norte da África, à Ásia Menor e até mesmo na Índia.

Além de contribuir com registros históricos fundamentais para a evolução científica, filosófica, política e poética da existência humana a tipografia, de acordo com Camargo (2003), descreve que a invenção de Gutenberg do século $\mathrm{XV}$, que foi a de associar e otimizar um conjunto de sistemas, isto é, a prensa e os tipos móveis, revolucionaram o progresso tecnológico com o acúmulo do conhecimento. Era o início da indústria, do processo de produção em série e 
uma revolução gráfica. Como resultado, uma gama de manuais tipográficos e novos desenhos de tipos, geralmente com o nome das fontes associados às famílias de gráficos e impressores.

Desde então, com a evolução da palavra e da representação gráfica para personificar um sentimento ou informação, torna-se indispensável um método de criação tipográfica para as artes visuais e para o design gráfico. A dependência da originalidade e do estímulo plástico dos tipos, passa a ser fundamental para apresentar ao leitor uma identificação, uma definição e uma decisão no ato do consumo das informações. Assim como o de representação corporativa, tribal ou ideológica.

A linguagem dos tipos, na criação e no ensino de normas e padrões, evoluíram generalizadamente para todos os povos ocidentais ao final do século 19, o que permitiu a criação e a popularização de diversos meios impressos e canais de transmissão de informações. Estes fatos ocorreram devido ao desenvolvimento industrial e ao barateamento do processo de impressão, com a consequente alfabetização dos povos. Jury (2006) afirma que nossas relações com as palavras nos permite a categorização de um mundo real que é construído dia a dia pelas linguagens gráficas criadas. O progresso cultural e urbano proporcionado pela revolução das tecnologias de impressão, com a reprodução de múltiplos exemplares de documentos, periódicos e livros, agregou a educação e a cultura, acúmulo de informações de aprendizagem e de ensino. Jury (2006) afirma ainda que a tecnologia tem sido o motor de impulso criativo para a tipografia, de transformação, determinando sua independência e a oportunidade para o experimento.

Para Lupton (2009, p. 8),

\begin{abstract}
Tipografia é uma ferramenta com a qual o conteúdo ganha forma, a linguagem ganha um corpo físico e as mensagens ganham fluxo social. Tipografia é uma área científica que estuda a influência estético-formal e a funcionalidade dos tipos de letra. Os aspectos comunicacionais dos tipos vão além da legibilidade do texto, eles conduzem e facilitam a leitura e é um viés cognitivo que transmite sentimentos.
\end{abstract}

Ainda nos dizeres de Lupton (2009, p. 13),

"Tipografia reflete uma tensão contínua entre a mão e a máquina, o orgânico e o geométrico, o corpo humano e o sistema abstrato. Essas tensões, que marcaram o nascimento das letras impressas há mais de quinhentos anos, continuam a energizar a tipografia hoje". 
A atuação do designer propõe a abertura de novas possibilidades que ampliem os seus horizontes sugerindo, a partir da riqueza de exemplos do passado, formas criativas e conscientes de se proceder no presente. $\mathrm{Na}$ composição com tipos há o emprego de significados atribuídos e das mais diferentes maneiras de se comunicar algo dentro de um limite e de um princípio dialético. A tipografia é traduzida com a expressão máxima do pensamento, da técnica verbal e da não-verbal que, por associações geométricas e imagens gráficas, consegue expressar diversos sentimentos e anseios do ser social. A informação que se propaga com os tipos são responsáveis pelo acúmulo do conhecimento e pela propagação de ideias; pela formação ideológica e de identidade; organização social, cultural e política pelo exercício da materialização de ideias (JURY, 2006).

Assim, faz-se necessário absorver um conjunto de regras e padrões que tornam a atividade de criação e composição com tipos uma importante área do design. Para se comunicar com tipos o designer irá aplicar os conceitos e fatores geométricos da letra, da linguagem e do alfabetismo visual, das ferramentas e softwares gráficos, como também sistemas de composição, diagrama e layout. Estes conceitos e fatores organizam toda a distribuição das informações propagadas, formam a sociedade industrial urbana, representam a própria tradução do cotidiano das cidades com diversos graus de utilidade e uso das coisas.

Os tipos e sua organização espacial estão em todos os lugares e em diferentes suportes como livros, jornais, revistas, embalagens, painéis, sinalização, etiquetas, formulários, aplicativos, softwares e uma infinidade de produtos e serviços. Estes, construídos e propagados pela articulação humana entre a fala e o pensamento são materializados na representação gráfica do desenho do alfabeto e sistemas visuais em paginação e layout.

\section{PROJETO TIPOGRÁFICO E LAYOUT}

Para o designer é importante rever a evolução da cultura gráfica do layout e do desenho da letra. O resgate tecnológico e experimental do trabalho com tipos e a evolução dos diagramas é fundamental para se entender o presente e projetar o futuro. O que seguiu com o tempo, desde a criação de Gutenberg no final da Idade Média, à criação digital das letras nos dias atuais, foi uma variedade de formas, cores, desenhos gráficos e impressão de tipos em produtos e serviços que tronaram a vida urbana mais fácil.

Portanto, é necessário o conhecimento do designer das particularidades do passado sobre a criação tipográfica, evolução dos processos de composição com tipos, de sua estrutura, peso, medida, formato, família e significação. É tamanha a riqueza da arte com tipos que o design gráfico conta a história através 
deles, de sua importância no meio social, do tratamento visual e estético de uma fonte e de sua caracterização no trabalho gráfico de uma época industrial, mecanizada e urbana. Durante todo o século $X X$, principalmente as últimas décadas, houve um avanço das tecnologias e da tipografia com a tendência para os aspectos funcionais e visuais e permitiram continuamente refletir história, estilo, arte, qualidade, grafismo e principalmente os procedimentos de uso e de leitura de dispositivos deste século (MOTA, 2009).

Jury (2006, p. 38), afirma que: "o primeiro manual de procedimentos gráficos teve origem na Inglaterra, em Londres de 1683, intitulado Mechanick of Execises. No ano de 1898, John Southwards publicou o manual Modern Printing: a Hanboock of the Principles e Pratice of Tipography and Pratice Arts".

Esta obra influenciou todo o padrão utilizado para a composição editorial como a valorização da imagem para a construção do layout. Consequentemente com as publicações de catálogos houve um aumento da disseminação do conhecimento industrial gráfico e as regras estabelecidas para a redação do texto e manipulação da imagem pela imprensa e artistas gráficos.

Mota (2009) afirma que nos primeiros anos de 1900 as artes gráficas assumem um caráter técnico de origem prático-funcional influenciando alguns grupos criativos e redutos europeus de artistas e arquitetos de vanguarda modernista. Um dos primeiros movimentos surgidos neste período é o Art Nouveau, um estilo que levou a consolidação do design gráfico como diferencial de planejamento, de projeto e fixou a página impressa com a elaboração de formatos de letras e de marcas comerciais. Os artistas gráficos, desta época, tornaram a comunicação visual mais dinâmica com a paginação, layout e a criação de modernos cartazes, bem como a utilização do jornal como veículo informativo para seus experimentos.

Segundo Pevsner (1994), estabeleceu-se com o Art Nouveau a transição entre o historicismo clássico e o Movimento Moderno, neste aspecto pode-se compará-lo ao Arts and Crafts, na Inglaterra do século XIX, ambos pretendiam renovar o artesanato e as artes decorativas junto ao desenvolvimento tecnológico e gráfico. $\mathrm{O}$ autor afirma que Willian Morris sugeriu novas linguagens para a tipografia e criou padrões para o design gráfico nos primeiros anos do século $X X$; suas ideias repercutiram mundialmente e seus ideais foram chamados de Arts and Crafts (artes e ofício). Morris propôs o redesenho dos caracteres e novos estilos de layout, além de defender a tipografia como forte expressão visual. A formação do design como área de conhecimento se aproxima, neste momento, da evolução da indústria de artefatos e indústria editorial dos meios de comunicação. Para Pevsner (1994), Morris é um verdadeiro profeta do século $X X$, suas ideias eram de compartilhamento e propagação da informação que mesmo contrário à maquinação e automação da indústria fez surgir novas 
responsabilidades ao design, bem como designá-lo como profissional. Morris, no entanto, deu origem a uma renovação total da ornamentação e da forma das artes e a defendia não apenas para alguns e sim para todos.

O início de século $X X$ foi um período de efervescência cultural e literária aos processos experimentais de alguns artistas que contribuíram para a formação do design e principalmente da evolução do layout e design de tipos. Garcia (2008), nos conta que a aproximação poética e a quebra de padrões em detrimentos aos novas linguagens comunicacionais trouxeram ao layout e à tipografia novos conceitos e a desconstrução do verbo. Um marco para a inovação experimental com tipos é a visualidade do texto proposta por Mallarmé, em Un coup de dés, publicação de 1897, em Paris. Os avanços tecnológicos da indústria gráfica permitiu a massificação editorial, também novos experimentos com tipos, como a impressão em larga escala de recursos tipográficos e imagens. Mallarmé utilizou-se das possibilidades criativas da diagramação atrelados ao som das palavras e a capacidade delas de evocar imagens, alterando a estrutura do texto, constata Garcia (2008).

Ainda segundo Garcia (2008), a conexão entre caligrafia e caligramas deu-se com os trabalhos tipográficos do poeta Guillaume Apollinaire, nos anos 20, no Art Nouveau. O poeta descreve visualmente os signos com a representação gráfica das letras. A inovação experimental do artista introduz a originalidade e criatividade no tratamento do texto e na composição tipográfica. Poesia e os tipos gráficos se aproximaram ainda mais com o futurismo de Marinetti, em Zang Tumb Tumb, uma publicação de 1914. Neste contexto os futuristas utilizam o desarranjo espacial e elementos de procedência variada regulando a visualidade. Em 1918, Raoul Hausmann, poeta futurista, publicou o poema optofonético que baseava-se na destruição do léxico para dar lugar ao som (GARCIA, 2008). Lia-se o irracional, um poema sonoro com registro tipográfico, tornava-se referência para a página e até mesmo para a deformação geométrica da letra. Numa convulsão social europeia de início de século, os alemães absorvem os ideais italianos e franceses do futurismo e do cubismo, e soma-se ao movimentos estéticos de vanguarda modernista com o construtivismo. Os alemães propuseram a união e a fusão da imagem com o texto para aumentar a força da palavra escrita. Na Rússia não foi diferente, contribuíram também nas primeiras décadas do século $X X$, com seu suprematismo de práticas tipográficas fundamentadas na geometria do layout e na caracterização ideológica das letras, conforme Garcia (2008).

Nas décadas de 20 e 30, do mesmo século, o design passou a influenciar positivamente sobre a comunicação e passou para uma posição de destaque na composição gráfica. Os artistas gráficos tiveram suporte de diversas áreas de conhecimento e principalmente da aplicação do projeto gráfico sugeridos por alguns movimentos de vanguardas modernistas como o Surrealismo, Art Decó e De Stijl. 
Hulrburt (2002) descreve esses movimentos como inovadores e contestadores dos movimentos anteriores de possibilidades criativas na página com uma resistência a simetria e ornamentos derivada das novas ideias tecnológicas da produção gráfica.

No movimento Art Decó os artistas gráficos fogem da simplicidade da apresentação e da funcionalidade da forma. A importância do movimento para a paginação e layout foi fazer uso dos espaços em branco e linhas de composição com destaque de títulos em negrito. A tipografia era bem elaborada com letras cheias e extremidades e cantos de complicado desenho. De Stjil significa "O Estilo" e foi um movimento que consolidou o design como diferencial e estratégico na composição e projeto. A característica principal do novo estilo era o trabalho bem elaborado dos tipos e rigorosa precisão da divisão dos espaços, o contraste entre tensão e equilíbrio, alcançados com a assimetria. A concepção formal do movimento foi resumida por Van Doesburg em 1928: "A linha reta corresponde à velocidade do transporte moderno; os planos horizontais e verticais à manipulação mais sutil, ou às mais simples tarefas da vida e da tecnologia industrial" (apud HURLBURT, 2002, p. 36).

A Bauhaus, fundada por Walter Gropius em 1919, Alemanha, teve profunda influência no design moderno. Foi a escola na qual reuniu diversos teóricos, artistas e arquitetos dedicados a preparar a sociedade para a revolução industrial. Os antecedentes históricos que demarcam a modernidade da Bauhaus derivam da Werkbund e, consequentemente, ao Arts and Crafts e ao Art Nouveau de Van de Velde uma vez que esta se formou pela Escola de Belas Artes e a de Artes Aplicadas, existentes em Weimar (PEVSNER, 1994).

A Bauhaus unia o conhecimento científico e técnico com a prática da criatividade. Gropius introduziu na Bauhaus processos e materiais tecnológicos em oficinas artesanais e teve profunda participação com importantes experiências em tipografia e no designgráfico. Esta escola trouxe para a paginação e layout diferentes contribuições e importantes mudanças no paradigma do design gráfico. As principais contribuições da Bauhaus foi a eliminação da letra maiúscula, com a criação de tipos mais simples, e a geometrização do layout.

Na década de 40, do mesmo século, houve uma melhor aproximação do leitor com ilustrações e plasticidade da página, os espaços brancos passaram a ter um significado marcado pela aceitação do grande público. As páginas impressas se tornaram estruturas organizadas e ordenadas como também a plasticidade passa a fazer parte das publicações cooperando com o desenvolvimento editorial e investimento comercial. Nesta década, mais precisamente em 1946, Lê Corbosier cria um sistema de design determinado Modulor. Este sistema adotou a razão áurea como parâmetro e segundo Hurlburt (2002, p. 81) foi qualificado por Albert Eisten como "uma série de dimensões que tornam o ruim difícil e o bom fácil". Com base no sistema Modulor foram 
desenvolvidos os diagramas que serviriam como padrão da página dividida em colunas e linhas que facilitariam o dia-a-dia dos mais diferentes tipos de criação gráfica.

A Escola de Ulm, fundada em 1952 na Alemanha, foi uma tentativa de restabelecer os conceitos da Bauhaus e introduziu principalmente o estudo da semiótica, da teoria da comunicação, a ergonomia e a cibernética aplicados ao design. Para o design gráfico Ulm trouxe novos experimentos com os métodos de impressão, que incluíam a utilização de tintas especiais e efeitos de textura, bem como novas propostas de layout no desenvolvimento do projeto gráfico para o jornal. A Escola foi até o ano de 1968 quando seus alunos e professores influenciaram o design de várias partes do mundo como nos países americanos com Tomás Moldonado, Max Bill e Gui Bonsipe. Segundo Dijon de Moraes (1999), por defender uma ideologia, por vezes, restritiva e pela defesa de um funcionalismo extremo, a Escola de Ulm teve curta duração, porém foi de suma importância para a formação do design gráfico.

As últimas três décadas do século $X X$ foram marcadas por profundas mudanças no processo comunicacional e constantes reformas gráficas. A valorização dos aspectos visuais na tipografia, novos processos de leitura e um mundo que se reorganiza em função de um projeto gráfico buscando a melhora da interface e usabilidade. Neste período de final de século a informatização dos processos e o desenvolvimento da tecnologia gráfica permitiram o aumento das possibilidades em utilizar recursos visuais. A valorização gráfica contemporânea de um projeto tipográfico e layout, ao final do século $X X$, ofereceu novos caminhos e oportunidades para o design no avanço criativo da expressão máxima das formas de pensamento pelo tipo e pela página.

\section{CONSTRUTIVISMO, CONCRETISMO E NEOCONCRETISMO NO DESIGN}

Construtivismo é o termo designado para o movimento de vanguarda russa de um grupo de artistas expressionistas reunidos em torno de Wasilli Kandinsky na Alemanha e do De Stijl que agrupou Piet Mondrian, Theo van Doesburg que estavam envoltos em pesquisas abstratas e o suprematismo por Kazimir Malevitch, em 1915 na Rússia (HURLBURT, 2002). Os experimentos do grupo de Mondrian deram origem ao Neoplasticismo, em 1917 na Holanda, no quais os artistas pregavam a abstração geométrica, formas simples e cores puras no trabalho artístico. Esta nova linguagem plástica, em defesa de um ideal universal, tinha como características principais a rejeição do espaço tridimensional pictórico e das curvas e a proposta de uma nova ordem da informação visual de pureza da informação gráfica. A arte e o manifesto 
neoplasticista era divulgado principalmente na revista De Stijl e para o construtivismo significou um apoio da filosofia da arte com espírito libertário e crítico na representação social.

Num ambiente revolucionário entre a antiga União Soviética e a Alemanha a origem do movimento construtivista propunha a socialização da arte e uma nova consciência cultural e política da produção industrial. O objetivo do construtivismo é a liberdade na criação com a utilização de fotomontagem, da colagem e tipografia nas artes aplicadas. O ideal construtivista foi muito influente para a formação da arte e do design moderno que inclui as experiências artísticas cubistas e a produção experimental da Bauhaus. Com a separação do grupo russo pelo exílio de seus integrantes houve uma grande influência de suas ideias na configuração do design em outros países, destacando o Brasil como precursor do movimento na América Lática, ou mesmo por ter uma identidade própria e uma nova linguagem gráfica autêntica e inovadora.

Segundo Teles (1978), em seus escritos sobre as vanguardas e o modernismo brasileiro, na América Latina em geral e no Brasil no período pós 2a Guerra Mundial, o construtivismo esteve presente para a formação de uma identidade nacional. Dentre os movimentos observados no país com influência do vanguardismo russo está o concreto de São Paulo (Grupo Ruptura) e no Rio de Janeiro (Grupo Frente). A investigação paulista do concretismo é centrada no conceito de pura visualidade da forma, o grupo carioca opõe-se ao paulista com maior articulação entre arte e vida e uma maior ênfase na intuição como requisito fundamental do trabalho plástico e artístico. O programa concreto parte de uma aproximação entre trabalho artístico e industrial que propõe renovação dos valores essenciais das artes visuais, por meio da geometria, produção industrial e com maior funcionalidade abstracionista. Em 1952, em São Paulo, os irmãos Augusto e Haroldo de Campos e Décio Pignatari editaram a revista Noigandres os quais formaram o grupo Ruptura com influência direta do De Stijl, da Bauhaus e da Ulm. No Rio de Janeiro, em 1954, o Grupo Frente tem como teóricos os críticos Mário Pedrosa e Ferreira Gullar. O grupo concreto carioca prega a experimentação das todas as linguagens, justaposição de elementos e maior utilização de recursos gráficos. Seu fundador é Aluísio Carvão e dentre seus membros estavam Décio Vieira, Lygia Clark, Lygia Pape e Hélio Oiticica (TELES, 1978).

O neoconcretismo é estabelecido com o manifesto de 1959, que reuniu Amílcar de Castro, Ferreira Gullar, Franz Weissmann, Lygia Clark, Lygia Pape, Reynaldo Jardim e Theon Spanúdis. O movimento de ruptura concreta é contra as ortodoxias construtivas e o dogmatismo geométrico, defendem a liberdade de experimentação e o retorno às intenções expressivas da subjetividade. Como resultado houve a expressiva recuperação das possibilidades criadoras do artista com novos modelos e uma aproximação entre artista e processo de trabalho. 
Os princípios do manifesto concreto e neoconcreto afastam da arte qualquer conotação lírica ou simbólica. O artista, manipulador de signos e portador da informação, terá maior autonomia para expressar-se no seu trabalho ou mesmo caracterizá-lo com uma identidade própria. Os objetos derivados desta relação verdadeira são definidos por eles mesmos, sem outras conotações, uma visão mais cética da natureza material e uma maior liberdade na criação e composição. Os grupos discutem pesquisas sobre percepção visual informadas pela teoria da Gestalt como também a defesa da integração da arte na sociedade urbana.

Estes movimentos contribuíram para o design com um novo conceito de layout, limpo, sem fios, vinhetas e maior aproveitamento do espaço branco. A evolução gráfica desencadeada pelo Concretismo e Neoconcretismo possibilitou a combinação de diagramas entre as páginas, a modulação geométrica, a variação de fontes, de pesos e interposição das grids editoriais.

Neste sentido, o design estrutura e redimensiona a criação tipográfica e os espaços da página contribuindo para tornar a informação legível e mais atrativa para o leitor através da criação e desenvolvimento de um projeto. Esta responsabilidade permite uma distribuição ordenada dos elementos constitutivos na área impressa em sistemas de composição já pré-determinados. O objetivo principal é otimizar a informação disponibilizada no veículo e garantir uma comunicação ágil e veloz de que tanto necessita o usuário contemporâneo.

\section{SISTEMAS TIPOGRÁFICOS DE KIMBERLY ELAM}

Sistemas tipográficos é um conjunto de normas e regras de composição divididas em técnicas visuais. Elam (2007) propôs quatro sistemas baseados em estudos da geometria, tipografia, diagrama e layout: axial, radial, modular e bilateral. O autor se baseou na aplicação de padrões e proporções da natureza e da regularidade espacial de diagramas e experimentos da história do design gráfico. Para Elam (2007), tipografia não existe somente para ser lida, mas também para ser vista. Pode-se irradiar: postura, seriedade, confiança, relaxamento e distanciamento dos tipos na criação e condução da leitura de um layout. A comunicação, para o autor, está na forma abstrata das letras e é uma das tarefas essenciais do designer que, além de criar tipos, deve ser capaz de interpretar e comunicar um texto em sua peça gráfica.

Neste sentido, a composição com tipos deve seguir um projeto em que considere alguns parâmetros geométricos, como a construção do diagrama para a criação da peça. A tipografia possibilita fazer com que os elementos básicos do alfabeto e a estrutura geométrica dos caracteres sejam únicos, com a mesma personalidade no desenho. Desta maneira, é possível com o diagrama compreender as variações de forma e mecânica do texto com versatilidade 
e estabilidade. Elam (2007) afirma que a tipografia é uma informação visual que quando compõe uma peça gráfica, deve ser racional e funcional, dando personalidade à composição. $\mathrm{O}$ autor propõe com os quatro sistemas, a possibilidade de um layout com limite matemático e padrão geométrico particularizados na anatomia do tipo e na construção geométrica da página e que servem como malha estrutural para a criação. Para Elam (2007), a aplicação dos sistemas vão desde a observação dos elementos básicos e do inter-relacionamento das partes do tipo como a unificação de características do diagrama.

\subsection{Sistema Axial}

O Sistema Axial dá-se quando no diagrama há quebra dos planos e divisão em verticais, horizontais ou diagonais, tornando a informação espacialmente distintas. Na divisão em linhas surgem áreas especiais que podem ser trabalhadas separadamente. No sistema pode ser percebido volume, espaço e movimento. Neste sistema existe um eixo princípio das direções ortogonais e as orientações das linhas consistem em tonar a percepção simétrica ou assimétrica, equilibrada ou desequilibrada.

A figura 1 ilustra o sistema axial proposto por Elam (2007). Na imagem percebe-se a força das linhas horizontais, verticais e diagonais e a quebra da regularidade das áreas preenchidas com tipos. As linhas partem o diagrama e formam áreas com contrastes que podem ser visualmente identificáveis com as informações importantes. Nota-se nas imagens da figura 1, o contraste tipográfico provocado nas áreas e nichos informativos.

\subsection{Sistema Radial}

Neste sistema alguns ou todos os elementos partem organizados de um ponto central para se estenderem em raios lineares ou circulares. A leitura depende das orientações e das direções das linhas. Neste sistema existe muito movimento no qual é fruto da utilização de todo o diagrama percorrido pela leitura. A cada divisão das extensões lineares ou circulares este sistema propõe uma novidade em busca do equilíbrio para a leitura das informações.

Os exemplos da figura 2 mostram o sistema radial com a utilização experimental de linhas orgânicas e circulares no diagrama. Este sistema exige de seu compositor o domínio espacial das forças, os pesos e as medidas de cada parte da informação. O sistema radial, como mostra na figura, provoca movimento e dinâmica na página, possibilita ao layout plasticidade e beleza na leitura dos verbetes. 
Figura 1 - Sistema Axial de composição proposto por Kymberli Elam.

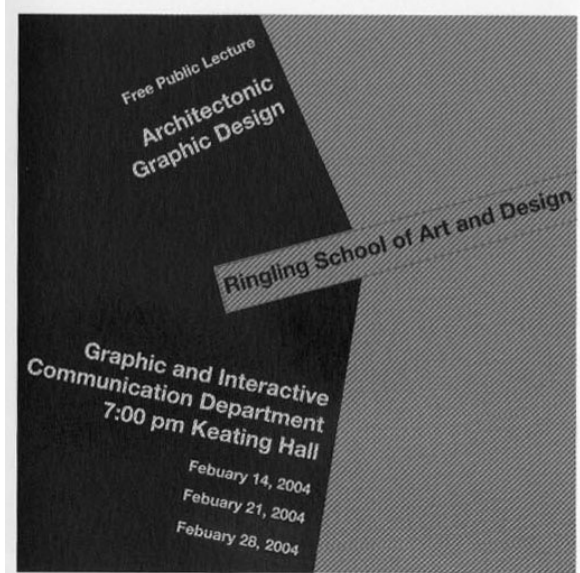

Loni Diep
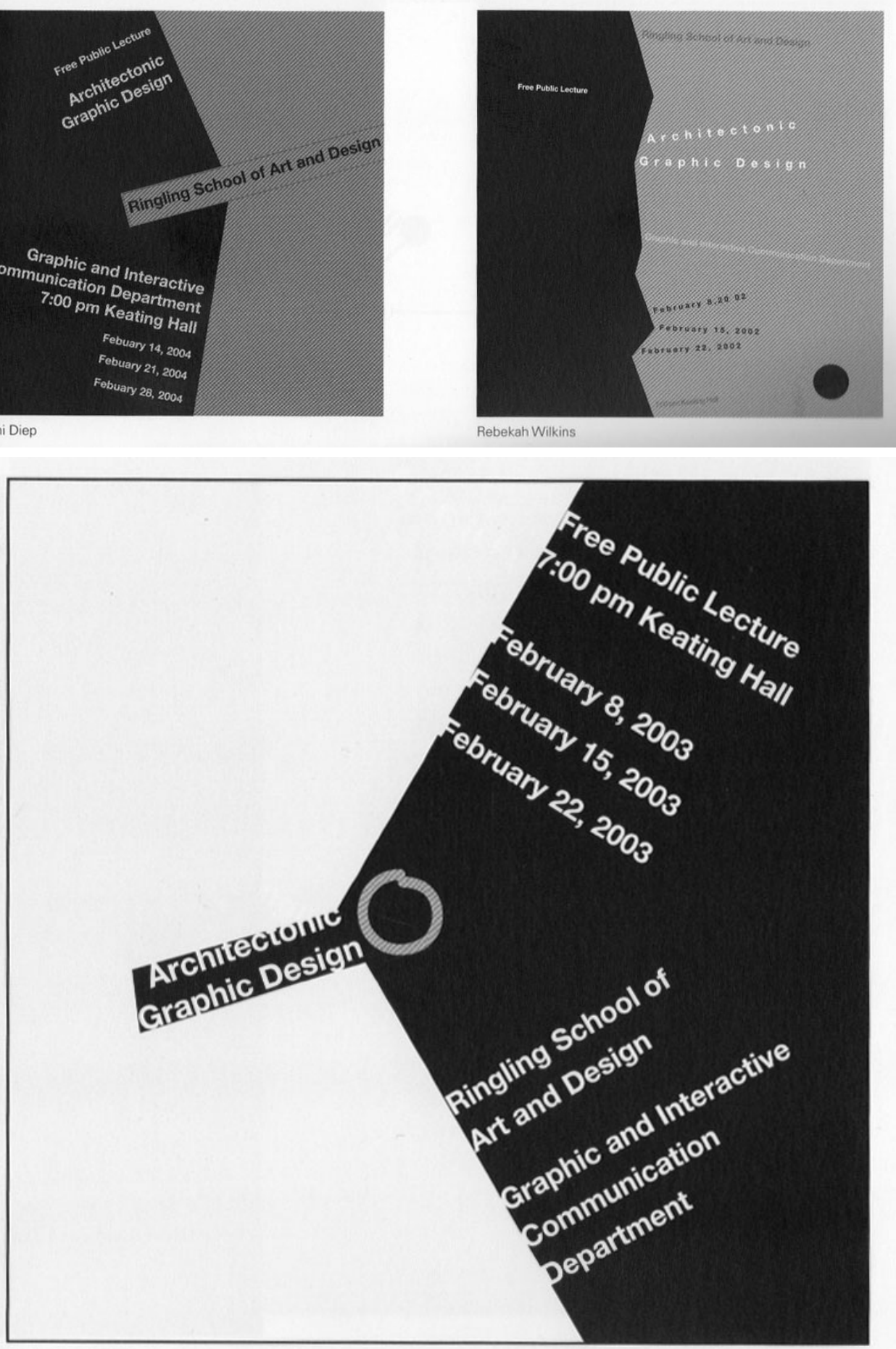

Rebekah Wilkins

Fonte: Elam (2007, p. 31).

\subsection{Sistema Modular}

O módulo é uma parte independente de um sistema que se repete em um padrão regular. Neste sistema há uma grade formada a partir de um módulo que permitirá novas construções a cada composição. O papel deste sistema é padronizar os espaços, sendo separados de maneira regular como estrutura, mas

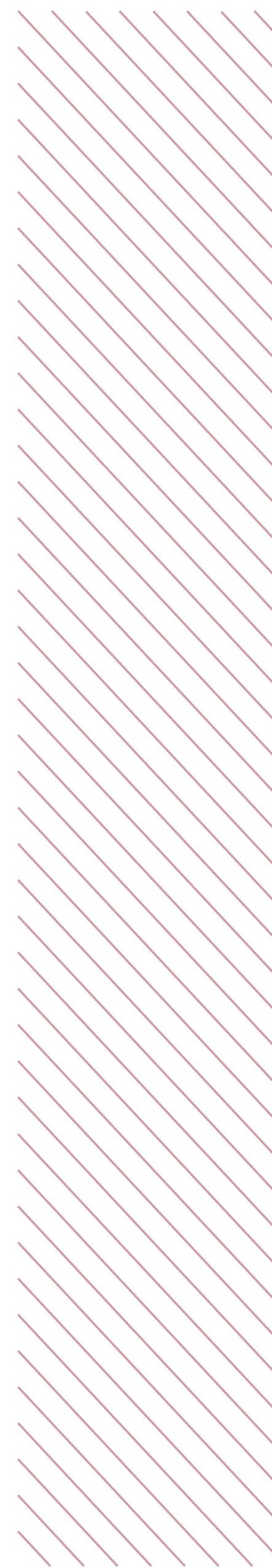


com abertura e fechamento de áreas nas quais conduzirão sequencialmente uma informação. Este sistema possui uma relação visual com linhas guias da página, a separação visual se dá através dos elementos que forçam a sequência da leitura de um elemento como colunas, quadros ou fios. Os módulos podem ser alternados, equilibrados ou não dentro do diagrama.

As imagens da figura 3 contém exemplos da dinâmica que o sistema modular proporciona na página. Com este sistema é possível criar texturas e volumes segregados de um centro informativo. Como nos exemplos da figura, a tipografia e os verbetes são quebrados em módulos e a leitura é feita através da percepção das partes divididas pelas linhas.

Figura 2 - Sistema Radial de composição proposto por Kymberli Elam.
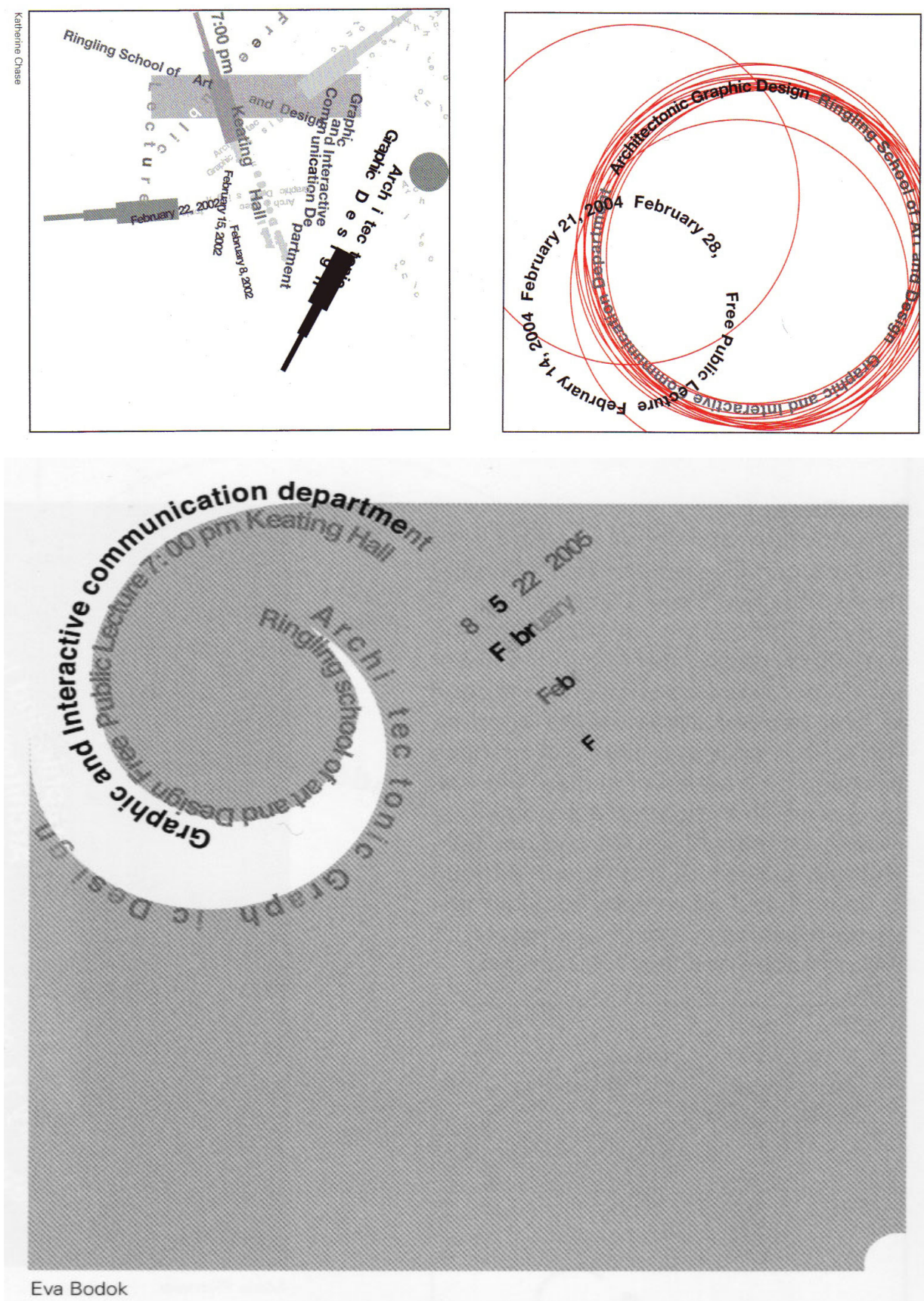

Fonte: Elam (2007, p. 67-69). 
Figura 3 - Sistema Modular de composição proposto por Kymberli Elam.
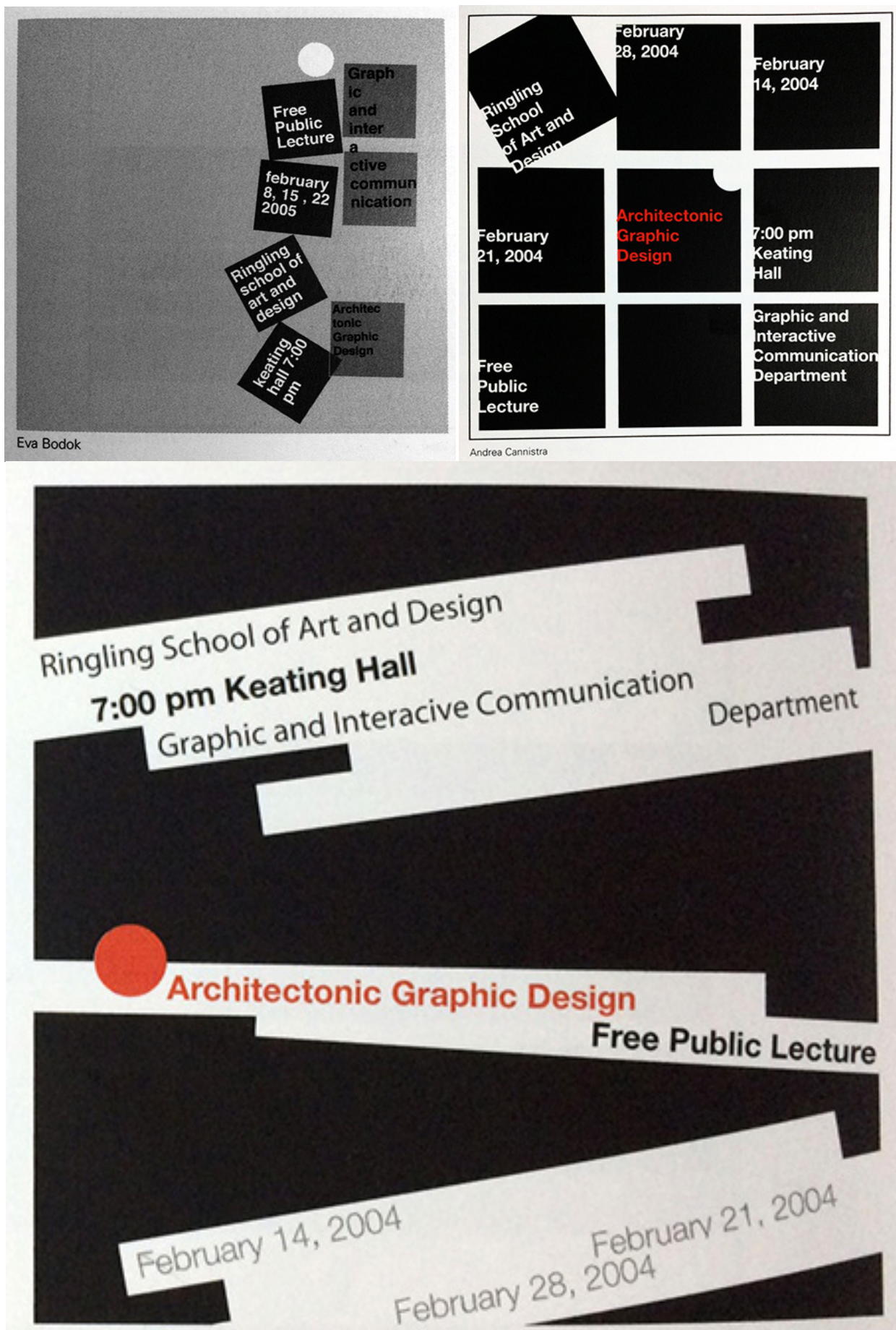

Sara Suter

Fonte: Elam (2007, p. 131 e 134).

\subsection{Sistema Bilateral}

Neste sistema existe um eixo visível que proporciona o equilíbrio e o peso proporcional a um centro. Simetria bilateral é quando há um espelhamento em uma parte refletida com um espelho, informações repetidas em partes divididas. Com esta divisão no diagrama a informação é centralizada, horizontal ou verticalmente, e a leitura dos tipos e massas de texto partem rigorosamente 
deste eixo. Este tipo de sistema permite ao compositor experimentar diversas formas de precisão visual de equilíbrio. Pode-se mudar o ponto geométrico central e dividir a página várias áreas na sequencia de leitura dos verbetes editoriais.

Nos exemplos da figura 4 percebe-se a simplicidade da divisão espacial e como é possível o espelhamento das informações de maneira equilibrada. Os modelos da figura 4 mostram que a distribuição dos tipos e do texto do sistema bilateral exige do compositor o contraste dos espacejamentos entre linhas e palavras, bem como o exagero visual de um elemento informativo centralizado.

Figura 4 - Sistema Bilateral de composição proposto por Kymberli Elam.
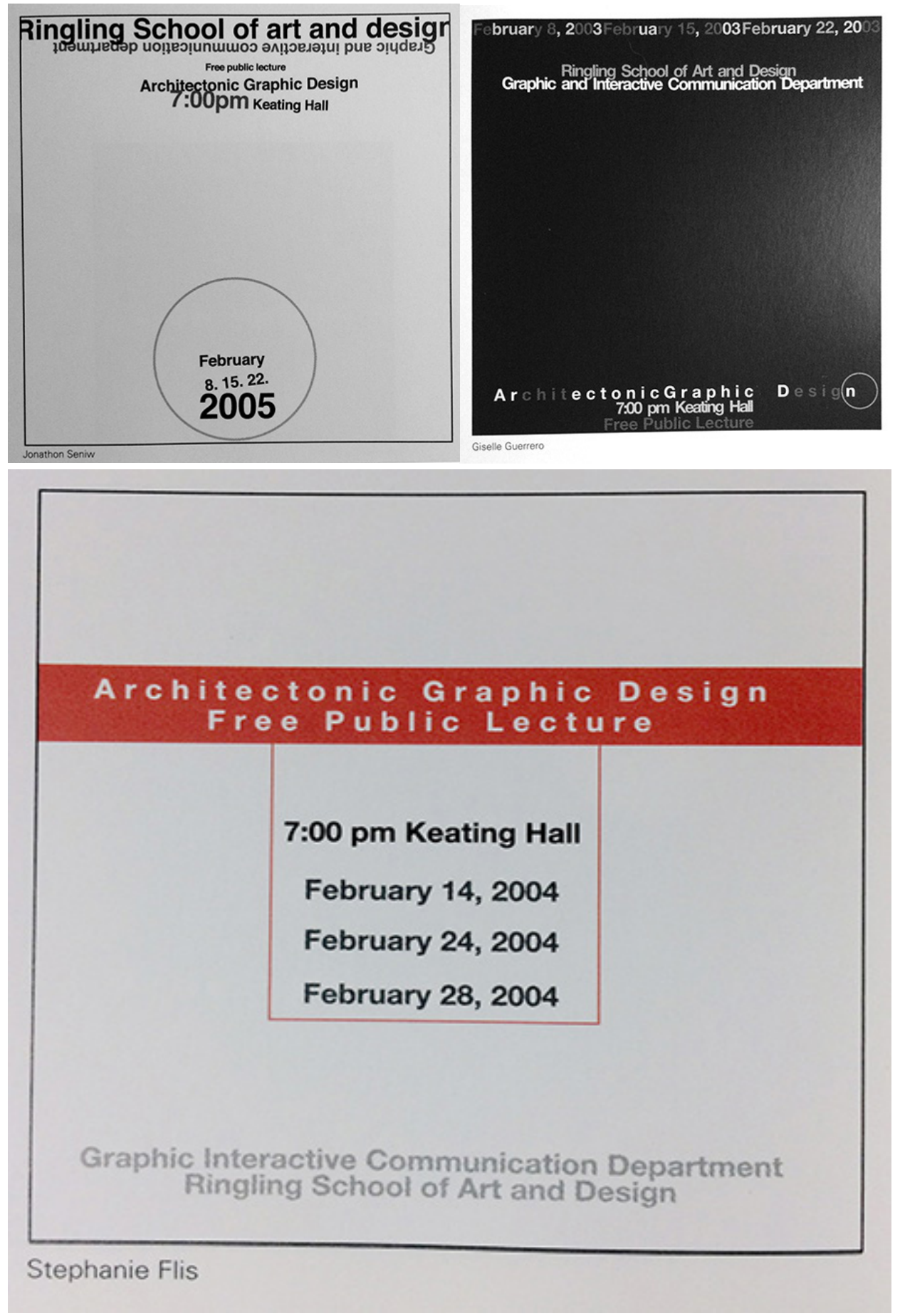

Fonte: Elam (2007, p. 147-148).

Projética, Londrina, v.9, n.2 supl. p. 107-124, nov. 2018 


\section{CONSIDERAC̣̃̃ES FINAIS}

Tais práticas e processos aqui apontados fazem parte do dia a dia dos designers gráficos, e também de muitos outros profissionais que se ocupam com a configuração visual da linguagem verbal. Aos artefatos gráficos produzidos por estes profissionais somam-se as letras escritas, desenhadas ou impressas presentes em mensagens visuais. Estamos, assim, imersos em um ambiente permeado de artefatos visuais contendo letras, números e sinais que competem por nossa atenção, colocando questões que demandam investigações mais aprofundadas no campo da linguagem tipográfica e seus sistemas. Muitas outras considerações podem ser feitas a partir deste ponto, indo do nível mais elementar, da letra ou do caractere, ao nível mais complexo dos textos agrupados em um volume. A análise sistemática da tipografia enquanto linguagem visível requer uma compreensão profunda dos aspectos formais, técnicos, históricos, cognitivos e culturais que envolvem a prática do design de tipos e do design com tipos, algo que esta reflexão pode oferecer.

Portanto, a partir daquilo que foi observado nesse artigo, podese propor um entendimento do design não como portador passivo de uma linguagem visual positivada e autônoma (baseada em abstrações), mas como uma linguagem em si que obedece a leis interconectáveis àquelas da linguagem verbal. Essa linguagem que é o design apresenta-se, por sua vez, de modo inter ou transdisciplinar num mercado sob a forma de retórica. Para cada projeto de design, camadas de retórica são construídas a partir de contextos, situações e subjetividades incomensuráveis, mas sempre em estado de observação pelo olhar atento do designer contemporâneo.

A principal contribuição deste estudo é servir como guia para estudantes, profissionais e pesquisadores em design gráfico. O trabalho revela a complexidade da linguagem tipográfica no processo de composição e prática projetual. Valoriza, também, a utilização de uma metodologia adequada que contribui para o aumento do grau criativo da peça. Os sistemas de Elan (2007) acrescenta, como técnica visual, novas possibilidades de distribuição e leitura dos elementos na página. No estudo, procurou-se resgatar a evolução histórica e o processo de leitura tipográfica para adequar o discurso teórico-prático do profissional nas linguagens de representação gráfica. 


\section{REFERÊNCIAS}

CAMARGO, Mário de (Org.). Gráfica: arte e indústria no Brasil. 2. ed. São Paulo: Bandeirantes, 2003.

DENIS, Rafael Cardoso. Uma introdução à história do design. São Paulo: E. Blücher, 2000.

ELAM, Kimberly. Typographic systems. New York, USA: Princeton Architectural Press, 2007.

FRUTIGER, Arian. Sinais e símbolos: desenho, projeto e significado. Tradução de Carina Jannini. São Paulo: M. Fontes, 1999.

GARCIA, Angelo Mazzuchelli. A literatura como design gráfico: da poesia concreta ao prema-processo de Wlademir Dias Pinto. 2008. Tese (Doutorado em Estudos Literários) - Faculdade de Letras da Universidade Federal de Minas Gerais, Belo Horizonte, 2008.

HURLBURT, Allen. Layout: o design da página impressa. Tradução de Edmilson O. Conceição e Flávio M. Martins. São Paulo: Nobel, 2002.

JURY, David. What is typography? Switzerland, UK: Rotovision, 2006.

LUPTON, Hellen. Pensar com tipos. Tradução de André Stolarski. São Paulo: Cosac Naify, 2006.

MORAES, Dijon de. Limites do design. São Paulo: Studio Nobel, 1999. 
MOTA, Marcelo José da. Design da notícia. 2009. Dissertação (Mestrado em Design) - Universidade Estadual Paulista, Bauru, 2009.

PEVSNER, Nikolaus. Os pioneiros do desenho moderno de William Morris a Walter Gropius. Tradução de João Paulo Monteiro. 2. ed. São Paulo: M. Fontes, 1994.

TELES, Gilberto Mendonça. Vanguarda Européia e modernismo brasileiro. Rio de Janeiro: Vozes, 1978. 